\title{
A quick needs assessment of key stakeholder groups on the role of family medicine in Zambia
}

\author{
J Sanders, ${ }^{1} \mathrm{MD} ;$ M Makasa, ${ }^{2} \mathrm{MD}$; F Goma,${ }^{3} \mathrm{PhD}$; E Kafumukache, ${ }^{4}$ MMedSci; M S Ngoma ${ }^{5} \mathrm{MRCP} ; \mathbf{S} \mathrm{Nzala},{ }^{6} \mathrm{MD}$ \\ ${ }^{1}$ Department of Family and Community Medicine, Faculty in the School of Medicine, Medical College of Wisconsin, Milwaukee, USA \\ ${ }^{2}$ Department of Community and Family Medicine, Faculty in the School of Public Health, University of Zambia, Lusaka \\ ${ }^{3}$ Centre for Primary Care Research, Faculty in the School of Medicine, University of Zambia, Lusaka \\ ${ }^{4}$ Department of Anatomy, Faculty in the School of Medicine, University of Zambia, Lusaka \\ ${ }^{5}$ Department of Paediatrics and Child Health, Faculty in the School of Medicine, University of Zambia, Lusaka \\ ${ }^{6}$ Department of Medical Education Development, Faculty in the School of Medicine, University of Zambia, Lusaka
}

Corresponding author: J Sanders (jsanders@mcw.edu)

\begin{abstract}
Background. Zambia is a nation of nine million people, and has too few physicians to meet the country's health needs. Following the strategy of other subSaharan countries, Zambia has developed a training programme in family medicine to help improve the medical competencies of its physician workforce. A needs assessment was undertaken to better understand the landscape into which Zambian family medicine is being placed.

Methods. In 2014, a nine-question survey in Likert-scale format was developed, validated, and then delivered to four stakeholder groups: (i) practicing clinical physicians, (ii) the general public, (iii) the University of Zambia's School of Medicine's academic faculty and (iv) medical students. The needs assessment was delivered through several different mechanisms: via web-based service, to respondents' email addresses; in paper form, to population samples of convenience; and verbally, through face-to-face encounters.

Results. The number of stakeholders from each group who responded to the needs assessment were: clinical physicians, 27; general public, 15; academic faculty, 14; and medical students, 31 . Five of the nine survey statements achieved super-majority consensus, with $>66 \%$ of stakeholders in each group agreeing. Two additional statements achieved a simple-majority consensus with $>50 \%$ agreement within each stakeholder group.

Conclusion. This survey suggests that there is a broad-based a priori understanding of family medicine in Zambia, and general agreement that its presence would be valuable to Zambia's healthcare system.
\end{abstract}

Afr J Health Professions Educ 2017;9(3):94-97. DOI:10.7196/AJHPE.2017.v9i3.831

General practitioners (GPs) have long been important for the delivery of healthcare services in Zambia, and they currently represent the largest class of physicians in the country. However, as the health needs of the Zambian population have become more complex, the training of the GP has not been able to keep pace. As a result, Zambia's healthcare workforce has been challenged to keep up with the country's increasingly complex health service demands.

Zambia is not alone in being confronted with a mismatch between the competencies of its healthcare workforce and the needs of the population. Many countries in the region face a similar set of issues, and have looked to family medicine as a strategy to improve their country's health outcomes. ${ }^{[1,2]}$ Family medicine is seen by the region's healthcare planners and administrators as an attractive solution to addressing some of the region's health needs, because it offers a broad scope of advanced medical competencies within the embodiment of a single practising physician.

From the mid-1960s until 2012, Zambia only had one medical school, which was situated in the country's capital, Lusaka. Initially, the educational focus was on training physicians to a GP's level. Training to a more advanced clinical level, such as adult medicine, paediatrics, general surgery and obstetrics and gynaecology, did not begin until the 1990s. Other speciality postgraduate programmes have been recently introduced, and now include orthopaedics, ophthalmology, anaesthesiology, psychiatry and infectious diseases.
Ironically, one of the consequences of training to a speciality level has been the diminished capacity of the Zambian health sector's ability to consistently provide full-service care to its patients. This is because medical specialists tend to aggregate towards more tertiary healthcare settings, making them less accessible to the general population. It is also true that in Zambia it is rare to find enough specialists in any one location to meet the needs of the presenting patients. ${ }^{[3-5]}$ This is especially so for the majority of Zambians, who live outside of large city centres. ${ }^{[6]}$

In 2011, the University of Zambia's School of Medicine committed itself to begin a postgraduate training programme in family medicine, with special focus on alleviating the shortage of specialist doctors at the district level. A 5 -year grant from the US government, the Medical Education Partnership Initiative, supported this commitment.

In a country with no tradition of family medicine as a medical speciality, it was not self-evident that a unipolar plan of action from the University of Zambia's School of Medicine would be sufficient for success. Accordingly, we undertook a needs assessment of different stakeholder groups within the country's healthcare landscape to better understand how family medicine might be received. A Medline search using the key words 'survey', 'needs assessment', 'family medicine' and 'Africa' yielded only one published report for comparison. ${ }^{[7,8]}$ To our knowledge, however, our study is the first a priori needs assessment in sub-Saharan Africa to critically examine the receptivity 
to family medicine within major stakeholder groups before any educational efforts were begun.

\section{Methods}

In 2014, an anonymous nine-question survey was developed using a common five-point Likert scale for answers. Items were scored ranging from 'strongly disagree' (1) to 'strongly agree' (5) (Table 1). The survey was validated for content by having the six members of the University of Zambia's School of Medicine's Working Group on Family Medicine review each statement and answer the survey for themselves. Each of the workinggroup members critically appraised the survey's statements for accuracy and validity. Additionally, representatives from each stakeholder group were approached in an ad hoc manner and were led through a facilitated process of progressive inquiry around each of the survey's statements. The iterative process continued until each statement was refined and considered valid for all target stakeholder groups.

Four key stakeholder groups were identified and targeted for solicitation about their participation in family medicine's future: faculty at the medical school who would have the responsibility to teach this new kind of postgraduate learner; medical students who would need to be attracted to this area of medicine and see a professional future for themselves within it; practising physicians who would need to make room within their ranks for graduates of family medicine; and the public at large, who, by being the end consumer of family medicine, would need to 'buy' what family medicine was 'selling' if there was going to be longterm sustainability. Criteria for inclusion included being $>18$ years of age and able to speak English. Three out of the four stakeholder groups speak English as a matter of their daily professional lives, and it is also the most widely spoken second language in Zambia, with even higher prevalence in the larger cities. At the time of the survey distribution, English was the exclusive language of instruction for all Zambian public schools. ${ }^{[9]}$ Respondents were drawn mostly from populations of convenience, such as the University of Zambia's School of Medicine faculty, who had come together for the purpose of another meeting, or a group of medical students between lectures. The academic faculty and the medical students were given paper-based surveys to fill out. Clinical physicians were contacted via a web-based software platform that delivered the survey to the email addresses of the physician members of the Zambian Medical Association. Members of the general public were approached in public areas of Lusaka, and the survey was delivered to

\section{Table 1 . The survey instrument}

Using a scale of $1-5$, please respond to the following statements:

$\begin{array}{llllc}1 & 2 & 3 & 4 & 5 \\ \text { Strongly disagree } & & & \text { Strongly agree }\end{array}$

I am familiar with family medicine as a medical speciality.

I know a family physician who practises in Zambia.

There is a need for training family physicians in Zambia.

Family medicine is important to Zambia's health.

Family medicine is well understood as a speciality.

Family medicine will be welcome within the Zambian medical profession.

Family-medicine physicians can be leaders in clinical care.

Family-medicine physicians are best suited for district healthcare.

Family-medicine physicians are best suited for District Health Officer positions. them by face-to-face interviews. The method of convenience sampling was chosen as a compromise to expedite this a priori study, because other higher-profile efforts to organise family medicine within the country were on the verge of being rolled out, and news of these efforts might have biased respondents. The same interviewer was used for all face-to-face interviews, so as to improve the reliability and accuracy of the reported results. The sample size was considered sufficient to detect differences among responses, with a total of at least 80 respondents.

This research was approved for human research by the University of Zambia's Research Ethics Committee (ref. no. FWA00000338/IR800001 131 of IORG0000774).

\section{Results}

The number of respondents from each subgroup was: clinical physicians, 27; general public, 15; academic faculty, 14; and medical students, 31 . Response rates were not calculated.

Average scores for each question from each stakeholder group were calculated (Fig. 1). Additionally, an inter-stakeholder group comparison was done on a question-by-question basis. Responses have been collapsed so

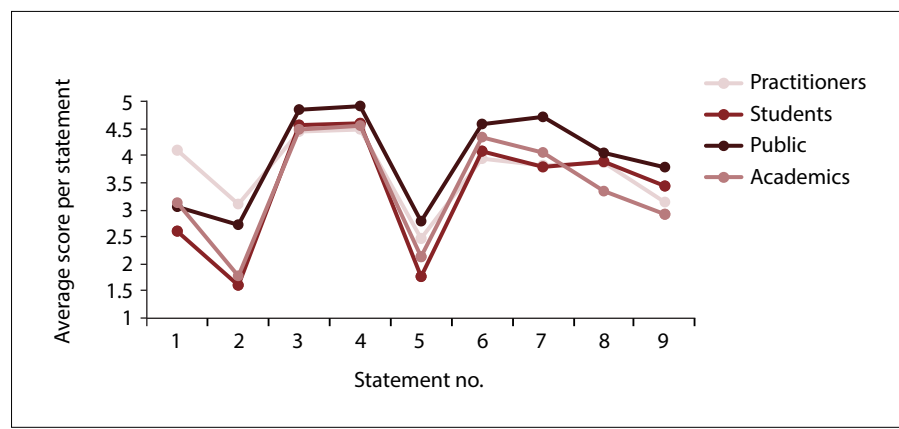

Fig. 1. Average numerical score for each statement by stakeholder grouping.

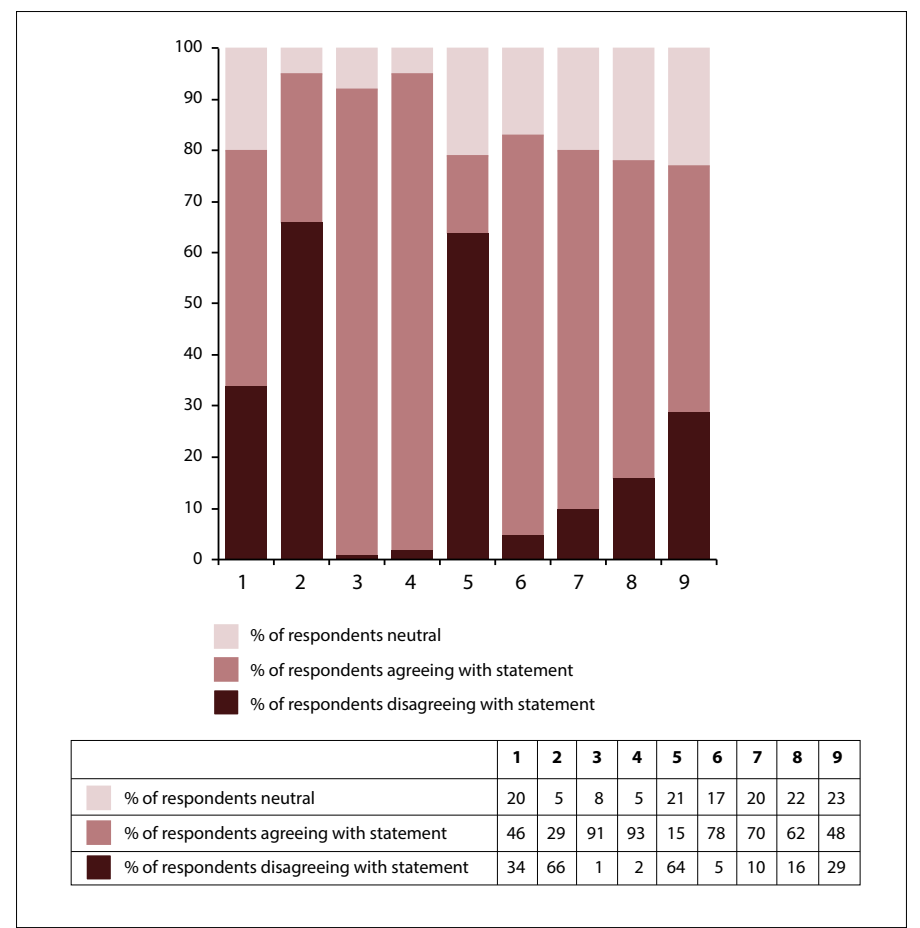

Fig. 2. Family medicine in Zambia: aggregated results. 
that 'disagree' and 'strongly disagree' are coupled, as are 'agree' and 'strongly agree' (Fig. 2).

There is wide-based concordance between the different stakeholder groups. More than $66 \%$ of each stakeholder population agreed that there is: - a lack of family medicine physicians currently in Zambia

- the desire for Zambia to have a training programme for family medicine physicians

- a recognition of the role that family medicine physicians can play in improving Zambia’s health landscape

- a sense that family medicine will be welcome within the professional ranks of medical specialists

- an acknowledgement of the central roles within the Zambian health system that family medicine physicians might inhabit.

In addition, $>50 \%$ of each stakeholder population agreed that:

- family medicine physicians would be well-suited to care for patients at the district level of health services.

- there is a need to educate the country at large about the speciality of family medicine.

\section{Discussion}

There was a broad-based consensus among the respondents from each of the four stakeholder groups, despite the disparity in their make-up. The respondents were made up of taxi drivers, bureaucrats, shopkeepers, students, restaurant patrons, academics, clinicians and a variety of others. All seemed to speak with one mind. For seven of the nine statements, more respondents answered in agreement with one another than in disagreement, and the two remaining statements that did not meet majority consensus failed to do so by less than $5 \%$ each.

One possible explanation for this general agreement across most statements is the simple nature of some of them. For example, the statement 'family medicine is important to Zambia's health' sounds very much like 'rain is important for Zambia's crops': it is hard to disagree with a statement having such an obvious answer. Yet this idea belies the deeper complexities of the survey's other statements, which were also answered with a high degree of intergroup correlation.

Statements 1, 2 and 5 all dealt with the respondents' familiarity with family medicine. Fig. 1 shows that there was fairly high congruency across all four of the respondent groups on this topic. Fig. 1 also shows that across all respondent groups, there was a high degree of intergroup congruency on what they all thought about the development of family medicine in Zambia (questions 3, 4, and 6).

It is interesting to note that despite a general unfamiliarity with the speciality, there is a general recognition that family medicine can play a central role in Zambia's healthcare landscape. Furthermore, respondents also noted the speciality's innate capacity to train physicians to become leaders within Zambia's healthcare hierarchy.

One possible explanation for the high intergroup congruency is that the idea of family medicine has already arrived in Zambia, even if its actual physical embodiment has yet to materialise. After all, at the end of the day, stakeholders from each group are, in some aspect, all consumers of the Zambian health system. The respondents might have intuitively recognised what other research has shown: a family-medicine physician represents a very efficient way to bring competent human resources to the clinical and managerial challenges facing stressed health systems. $[10,11]$

This survey and its results proved to be highly beneficial to the momentum of garnering stakeholder buy-in for family medicine's continued development in Zambia. The details of the evolution of family medicine in Zambia, and the road ahead, are described elsewhere, and are outside of the scope of this article. ${ }^{[12,13]}$

There are some structural limitations to our survey. Our survey was limited in that it only included speakers of English. The vast majority of Zambians speak a mother tongue other than English. As a result, there might have been some misunderstandings of the survey's statements, despite our pre-testing validation, and the respondents might have been skewed towards those belonging to a more educated or merchant class. Additionally, the 'general public' group was drawn solely from the capital city of Lusaka. The rural inhabitants of Zambia, for whom family medicine is being expressly developed, were not consulted, and might have opinions significantly different from their urban-dwelling countrymen. Nonetheless, the survey's findings are interesting and give us an indication of attitudes and knowledge about family medicine in Zambia. However, due to the limited sample size, these findings cannot be generalised.

\section{Conclusion}

Our survey demonstrated that the idea of family medicine was broadly recognised by the population sampled, and that there was wide-based receptivity to its local development. These findings could be used as a basis for developing family medicine programmes in Zambia. Further, other academic medical centres looking to begin family medicine might also use these results as a basis for their own stakeholder inquiries.

\section{Acknowledgements. None.}

Author contributions. JS was responsible for study design, oversight of study activity, data analysis and development of the manuscript. MM was responsible for data collection, data analysis and development of the manuscript. FG was responsible for the development of the manuscript. EK was responsible for study design and the development of the manuscript. SN was responsible for study design, human ethics committee application and development of the manuscript. MSN was responsible for the development of the manuscript.

Funding. There was no external funding for this study.

Conflicts of interest. None.

1. Flinkenflogel M, Essuman A, Chege P, Ayankogbe O, Maeseneer J. Family medicine training in subSaharan Africa: South-South cooperation in the Primafamed project as strategy for development. Fam Prac 2014;31(4):427-436. https://doi.org/10.1093/fampra/cmu014

2. Hellenberg D, Gibbs T. Developing family medicine in South Africa: A new and important step for medical education. Med Teach 2007;29(9-10):897-900. https://doi.org/10.1080/01421590701827890

3. Atkinson S, Ngwengwe A, Macwangi M, Ngulube T, Harpham T, O'Connell A. The referral process and urban healthcare in sub-Saharan Africa: The case of Lusaka, Zambia. Soc Sci Med 1999;49(1):27-38. https://doi org/10.1016/s0277-9536(99)00072-6

4. Few R, Harpham T, Atkinson S. Urban primary healthcare in Africa: A comparative analysis of city-wide public sector projects in Lusaka and Dar es Salaam. Health Place 2003;9(1):45-53. https.//doiorg/10.1016/s13538292(02)00029-1

5. Zulu J, Michelo C, Msoni C, Hurtig A, Byskov J, Blystad A. Increased fairness in priority setting processes within the health sector: The case of Kapiri-Mposhi District, Zambia. BMC Health Serv Res 2014;14:75. https://doi the health sector: The case of Kapiri-Mposhi District, Zambia. BMC Health Serv Res 2014;14:75. https:/do

6. Ferrinho P, Siziya S, Goma F, Dussault G. The human resource for health situation in Zambia: Deficit an maldistribution. Hum Resour Health 2011;9:30. https://doi.org/10.1186/1478-4491-9-30 


\section{Short Research Report}

7. Gossa W, Wondimagegn D, Mekonnen D, Eshetu W, Abebe Z, Fetters M. Key informants' perspectives o development of family medicine training programs in Ethiopia. Adv Med Educ Pract 2016;7:261-269. https:/ doi.org/10.2147/amep.s94522

. Essuman A, Anthony-Krueger C, Ndanu TA. Perceptions of medical students about family medicine In Ghan Ghana Med J 2013;47(4):178-184

9. Lusaka Times. Use of local language as a medium of instruction to be implemented next year. 18 January 2013 https://www.lusakatimes.com/2013/01/18/use-of-local-languages-as-media-of-instruction-to-be-implementednext-year-for-pre-grade-4/ (accessed 2 August 2017).

10. Starfield B. Is primary care essential? Lancet 1994;344(8930):1129-1133. https://doi.org/10.1016/s01406736(94)90634-3
11. Starfield B, Leiyu S, Macinko J. Contribution of primary care to health systems and health. Milbank Q 2005;83(3):457-502. https://doi.org/10.1111/j.1468-0009.2005.00409.x

12. Makasa M, Nzala S, Sanders J. Developing family medicine in Zambia. Afr J Prm Health Care Fam Med 2015;7(1). https://doi.org/10.4102/phcfm.v7i1.909

13. Sanders J, Makasa M, Goma F, Kafumukache E, Ngoma M, Nzala S. Developing a family medicine post-graduate training program in Zambia. Fam Med 2016;48(7):517-522. https://doi.org/10.4102/phcfm.v7i1.909

Accepted 3 November 2016. 